\title{
Improvements in WRF simulation skills of southeastern United States summer rainfall: physical parameterization and horizontal resolution
}

\author{
Laifang $\mathbf{L i} \cdot$ Wenhong $\mathbf{L i} \cdot$ Jiming Jin
}

Received: 22 July 2013/ Accepted: 23 December 2013

(c) Springer-Verlag Berlin Heidelberg 2014

\begin{abstract}
Realistic regional climate simulations are important in understanding the mechanisms of summer rainfall in the southeastern United States (SE US) and in making seasonal predictions. In this study, skills of SE US summer rainfall simulation at a $15-\mathrm{km}$ resolution are evaluated using the weather research and forecasting (WRF) model driven by climate forecast system reanalysis data. Influences of parameterization schemes and model resolution on the rainfall are investigated. It is shown that the WRF simulations for SE US summer rainfall are most sensitive to cumulus schemes, moderately sensitive to planetary boundary layer schemes, and less sensitive to microphysics schemes. Among five WRF cumulus schemes analyzed in this study, the Zhang-McFarlane scheme outperforms the other four. Further analysis suggests that the superior performance of the Zhang-McFarlane scheme is attributable primarily to its capability of representing rainfall-triggering processes over the SE US, especially the positive relationship between convective available potential energy and rainfall. In addition, simulated rainfall using the Zhang-McFarlane scheme at the $15-\mathrm{km}$ resolution is compared with that at a $3-\mathrm{km}$ convection-permitting resolution without cumulus scheme to test whether the increased horizontal resolution can further improve the SE US rainfall simulation. Results indicate that the simulations at the $3-\mathrm{km}$
\end{abstract}

\section{Li $(\bowtie) \cdot$ W. Li}

Earth and Ocean Sciences, Nicholas School of the Environment and Earth Sciences, Duke University, 322 Old Chem. Bldg, P.O. Box 90227, Durham, NC 27708, USA

e-mail: laifang.li@duke.edu

J. Jin

Department of Watershed Sciences and Department of Plants, Soils and Climate, Utah State University, Logan, UT 84322, USA resolution do not show obvious advantages over those at the $15-\mathrm{km}$ resolution with the Zhang-McFarlane scheme. In conclusion, our study suggests that in order to obtain a satisfactory simulation of SE US summer rainfall, choosing a cumulus scheme that can realistically represent the convective rainfall triggering mechanism may be more effective than solely increasing model resolution.

Keywords Southeastern United States - Summer rainfall - Weather research and forecasting (WRF) model . Cumulus parameterization scheme $\cdot$ Horizontal resolution

\section{Introduction}

The southeastern United States (SE US) is one of the fastestdeveloping regions in the nation. With its growing population and economy, warm-season precipitation plays an increasingly more important role in many aspects of regional sustainability, including hydrology, ecology, and agriculture (e.g., Riha et al. 1996; Manuel 2008; Martinez et al. 2009). Thus, accurate regional climate simulations for the SE US are important to its summer rainfall predictions.

Such a need, however, is hampered by the lack of satisfactory climate simulations over the SE US using either general circulation models (GCMs) or regional climate models (RCMs). Limitations of GCMs in simulating SE US summer rainfall are due mainly to their relatively coarse resolution $(\sim 200 \mathrm{~km})$ and unrealistic model physics (Taylor et al. 2012). Thus, these models are unable to provide reliable details of SE US climate systems at spatial scales of $<200 \mathrm{~km}$ (Pielke 2002; Mearns et al. 2003; Castro et al. 2005; Feser et al. 2011; Li et al. 2013b).

The complexity of summer rainfall in the SE US originates from the interweaving of land-sea distribution, 
complex terrain, diversified vegetation, land use/land cover change, as well as other factors and processes such as sea surface temperature. Over the coastal regions, summer rainfall is influenced by land-sea breezes and hurricane landfallings (Knight and Davis 2007), and the Appalachian Mountains often induce orographically uplifted rainfall. In addition, the passage of frontal systems also contributes to SE US summer rainfall (Kunkel et al. 2012). Differences in the factors that control rainfall in different subregions of the SE US make the summer rainfall highly heterogeneous (e.g., Stooksbury and Michaels 1991; Baigorria et al. 2007; $\mathrm{Li}$ et al. 2013a). These spatially heterogeneous features cannot be well represented by GCMs due to their coarse resolution and oversimplified physics (Taylor et al. 2012). Thus, dynamical downscaling with RCMs that have sophisticated structure and physics could be an effective way to better represent SE US summer rainfall systems (e.g., Giorgi and Mearns 1999; Leung et al. 2003; Castro et al. 2005; Mearns et al. 2012).

However, the SE US is a region where satisfactory RCM simulation skill has not yet been achieved (e.g., Lo et al. 2008; Walker and Diffenbaugh 2009; Mearns et al. 2012; Bowden et al. 2013). Previous studies have found that the RCMs participating in the North American Regional Climate Change Assessment Program (NARCCAP) show bias in warm-season precipitation over the SE US. In particular, the Weather Research and Forecasting (WRF) model in NARCCAP simulates a dry bias (about $40 \%$ ) in summer rainfall, whereas the Regional Climate Model version 3 (RegCM3) and the fifth-generation Pennsylvania State University-National Center for Atmospheric Research (NCAR) Mesoscale Model (MM5) simulations indicate a wet bias (Mearns et al. 2012). The biases of these RCMs in downscaled summer rainfall limit their ability to predict the future summer climate in the SE US. Thus, exploring RCM simulation skills of SE US summer rainfall and understanding the underlying physical mechanisms are important to fulfilling the community's need for reliable regional climate information.

The RCM simulation skills in regional climate usually depend on the initial conditions (ICs), lateral boundary conditions (LBCs), level of constraint toward driving data, physical parameterizations, and model resolutions (e.g., Christensen et al. 2007; Lo et al. 2008; Foley 2010; Rummukainen 2010; Feser et al. 2011). The sensitivity of SE US summer rainfall to the configuration of LBCs has been emphasized in previous studies (e.g., Seth and Giorgi 1998; Xue et al. 2007). Differences in the configuration of LBCs can influence the simulated upper tropospheric jet, large-scale moisture transport pattern, and relative humidity field (Xue et al. 2007), which dynamically and thermodynamically affect SE US summer rainfall (Wang et al. 2010; Li et al. 2013a). Generally, previous RCM experiments have suggested that bias in SE US rainfall simulation caused by LBCs could be largely reduced by configuring the southern boundary of the domain north of the tropics (Liang et al. 2001; Xue et al. 2007).

This study aims to understand the RCM simulation skills of SE US summer rainfall associated with the other two factors: physical parameterization scheme and model resolution. Analyzed from the climate perspective, the specific scientific questions addressed in this study are: (1) How sensitive are SE US summer rainfall simulations to different physical parameterization schemes, and what combination of physical parameterization schemes can optimize simulations of SE US summer rainfall? (2) Through what physical mechanisms do the physical parameterization schemes influence SE US summer rainfall simulation skills? (3) Since the subgrid-scale parameterization schemes usually cause uncertainties in rainfall simulations, could an increase in model spatial resolution help reduce such uncertainties and improve simulations of SE US summer rainfall? The answers to these questions are sought by performing sensitivity tests and using a processbased evaluation technique.

The remainder of this paper is organized as follows. In Sect. 2, we describe rainfall observations, the driving reanalysis data, the configuration of the WRF model, and the data analysis method. The influence of parameterization schemes on SE US summer rainfall simulations and their physical mechanisms are presented in Sect. 3. A discussion of the resolution dependence of WRF simulations appears in Sect. 4. In the last section, conclusions are given.

\section{Data, methods, and model}

\subsection{Rainfall observations and driving reanalysis data}

In this study, rainfall observations are obtained from the Climate Prediction Center (CPC) unified daily precipitation archive (Higgins et al. 2000). The CPC is gridded observation data with a spatial resolution of 0.25 degree $(\sim 25-\mathrm{km})$. The SE US is defined as the terrestrial domain over $23.5^{\circ} \mathrm{N}-$ $36.5^{\circ} \mathrm{N} ; 91^{\circ} \mathrm{W}-76^{\circ} \mathrm{W}$ (Wang et al. 2010 ; Li et al. 2011). The reliability of CPC precipitation data over the SE US has been verified by Li et al. (2013a). The summer season is defined as June-July-August (JJA); the seasonal mean thus refers to the daily precipitation averaged over JJA.

Climate forecast system reanalysis (CFSR) data (Saha et al. 2010) is adopted in this study to provide initial and boundary conditions for the simulations. The CFSR is a global reanalysis dataset, with a horizontal resolution of $0.5^{\circ} \times 0.5^{\circ}$ and 38 pressure levels. The dataset is available with a 6-h increment. In our analysis, simulations driven by CFSR data are compared with those driven by the North 
American Regional Reanalysis (NARR, Mesinger et al. 2006), the National Centers for Environmental Prediction (NCEP)-Department of Energy (DOE) Reanalysis 2 (NCEP-R2, Kanamitsu et al. 2002) and the European Centre for Medium-Range Weather Forecasts Interim reanalysis (ERI) products (Dee et al. 2011) and find that the choice of reanalysis forcing data does not influence summer rainfall simulations over the SE US in a discernible way (not shown).

\subsection{Selection of sample simulation periods}

The focus of this study is the dynamical downscaling skills of WRF to simulate SE US summer rainfall from a climate perspective. Previous studies have suggested that WRF simulation results vary among weather events (Bukovsky and Karoly 2009). Thus, the simulation period should be determined objectively to avoid the uncertainties introduced by specific weather events.

In this study, our simulations are focused on a onesummer period in which the precipitation pattern for the SE US mimics its climatology during 1948-2010. To identify such a summer period, we calculate the pattern correlation coefficient (PCC) and root mean square error (RMSE) between the precipitation pattern of each summer and its climatology during 1948-2010. An optimization algorithm is then applied to select the sample rainfall case for the WRF simulation. In this algorithm, the PCC (RMSE) calculated for each summer is ranked from high to low (low to high). The final rank for each summer period is calculated by combining the PCC and RMSE ranks. The period with the highest combined rank is then selected as the sample case for the WRF sensitivity experiment.

The averaged rainfall during any specific period with a running window of $l$ days is expressed as $x$, and the 19482010 JJA rainfall climatology is expressed as $y$. The PCC and RMSE are defined in Eqs. (1) and (2), respectively. In both equations, $N$ is the number of grid points over the $\mathrm{SE}$ US domain. The PCC and RMSE are calculated with various running window lengths $(l)$ : 7-, 11-, 15-, 21-, and 31day.

$$
\begin{aligned}
& \operatorname{PCC}(l)=\frac{\sum_{i=1}^{N}\left[\left(x(l)_{i}-\overline{x(l)}\right)\left(y_{i}-\bar{y}\right)\right]}{\left[\sum_{i=1}^{N}\left(x(l)_{i}-\overline{x(l)}\right)^{2}\right]^{\frac{1}{2}}\left[\sum_{i=1}^{N}\left(y_{i}-\bar{y}\right)^{2}\right]^{\frac{1}{2}}} \\
& \operatorname{RMSE}(l)=\left[\frac{1}{N} \sum_{i=1}^{N}\left(x(l)_{i}-y_{i}\right)^{2}\right]^{\frac{1}{2}}
\end{aligned}
$$

Figure 1a shows the averaged PCC versus the running window length. As the window length increases, the PCC increases, indicating that rainfall with increased temporal

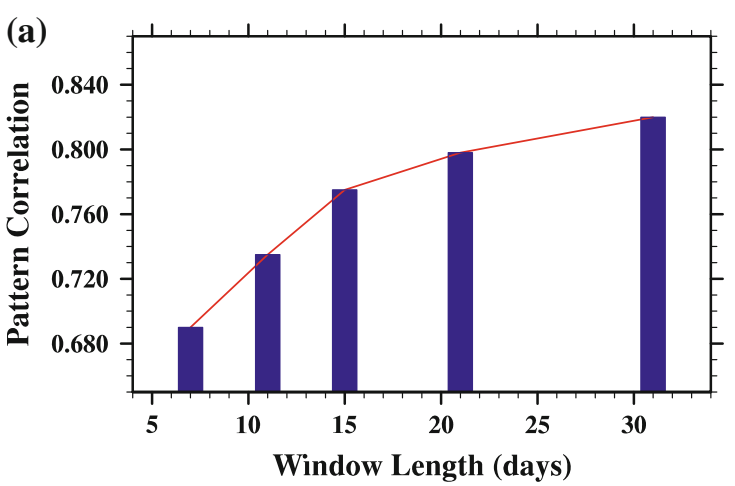

(b)

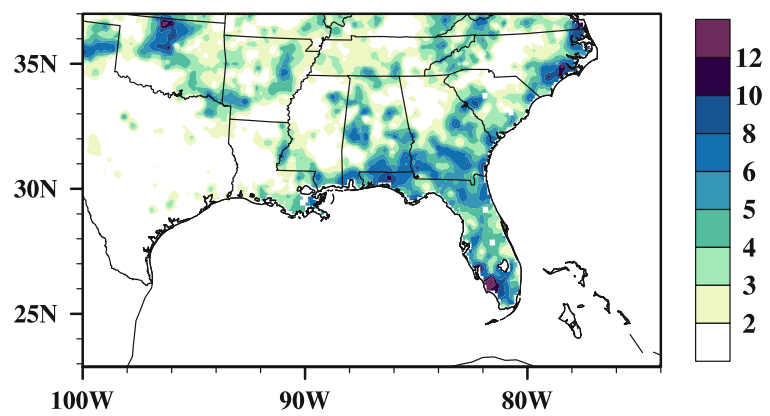

Fig. 1 a Maximum likelihood estimation of pattern correlation coefficients between running averaged precipitation and CPC SE US summer precipitation climatology (blue bars). The $\mathrm{x}$-axis is the length of the running window, and the y-axis is the pattern correlation coefficients; b SE US precipitation averaged over Aug. 01-Aug. 15, 2009 (shaded, unit: $\mathrm{mm} \mathrm{day}^{-1}$ )

scales better resembles the climatological pattern. Statistically, this result suggests that rainfall averaged over a short period ( $<10$ days) may not well represent a climatological pattern. Thus, good simulation of a specific rainfall event by WRF is not sufficient to ascertain its ability to simulate rainfall climatology, which is consistent with Bukovsky and Karoly (2009). The increased PCC, however, gradually saturates as the running window increases to 15 days (Fig. 1a). From the 7-day to the 15-day running windows, the averaged PCC increases from 0.68 to 0.77 , whereas as the window continues to increase to 31 days, the PCC increases only slightly, by 0.04 (Fig. 1a). The PCC results suggest that the 15-day window should be sufficient to obtain a reasonable climate simulation over the SE US; thus we chose a cut-off window of 15 days. A 15-day rainfall case would be selected for WRF simulation using the aforementioned optimization algorithm.

Over 1948-2010, we finally select the period of Aug. 01-Aug. 15, 2009 (Fig. 1b), for the sensitivity simulation period with the highest combined rank. All sensitivity experiments are performed using this sample period. The robustness of the conclusions from the sensitivity experiments is confirmed using a 10-summer (2001-2010) simulation. It is noteworthy that the optimization algorithm is 


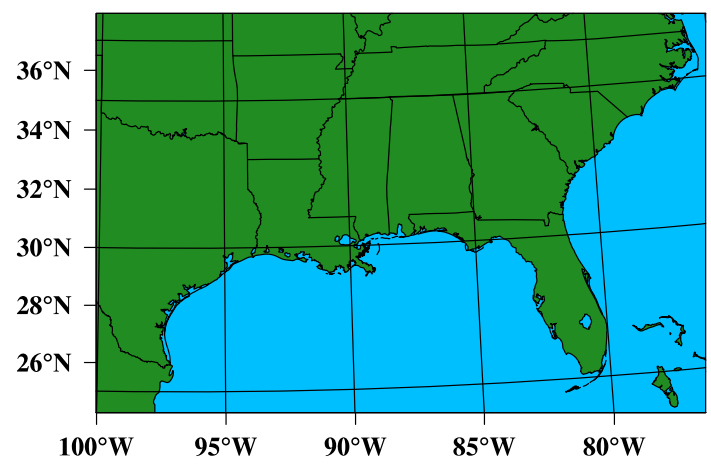

Fig. 2 The southeastern US domain used in the WRF simulations

designed to select a best representative case of rainfall climatology, rather than that of an extreme event such as a drought or flooding event. Thus, the conclusions in this study apply mainly to the WRF simulation of mean rainfall over the SE US for summer. Different metrics are needed to evaluate extreme rainfall events, which is beyond the scope of this study.

\subsection{Model descriptions and experiment setups}

The RCM used in this study is the WRF model with the Advanced Research WRF (ARW) dynamic core version 3.4 (Skamarock et al. 2008). The WRF is a nonhydrostatic, terrain-following, eta-coordinate mesoscale modeling system that has been widely used for operational forecasting and regional climate applications (e.g., Mearns et al. 2012).

To study the SE US summer rainfall, the model domain is centered at $30^{\circ} \mathrm{N}, 88^{\circ} \mathrm{W}$. The lateral boundary is composed of a 1-point specified zone and a 4-point relaxation zone to smooth potential pseudo-disturbances caused by numerical calculation ${ }^{1}$ (Fig. 2). The horizontal coordinates use the Lambert conformal conic projection with standard parallels at $30^{\circ} \mathrm{N}$ and $60^{\circ} \mathrm{N}$. The model consists of 38 vertical layers, and the top level is set to $50 \mathrm{hPa}$.

The physical parameterization schemes used in this study include the Dudhia shortwave radiation (Dudhia 1989), Rapid Radiative Transfer Model (RRTM) longwave radiation (Mlawer et al. 1997), and Noah land surface model (Chen and Dudhia 2001). In our experiment, the microphysics, planetary boundary layer physics, and cumulus schemes vary between different simulations to test the sensitivity of SE US rainfall to the choice of these parameterization schemes. For the control experiment, the Thompson microphysics scheme (Thompson et al. 2008), the Betts-Miller-Janjic (BMJ) cumulus scheme (Janjic 1994, 2000), and the Bougeault-Lacarrère (BouLac) planetary boundary layer physics scheme (Bougeault and

\footnotetext{
${ }^{1}$ When computing the skill scores of rainfall simulations, we only consider the rainfall over the terrestrial SE US.
}

Lacarrere 1989) are first selected and additional justification is given in Sect. 3.2. For the sensitivity experiments, the WRF model is initialized on Jul. 27, 2009, and run through Aug. 15, 2009. The first 5 days are discarded as spin-up. ${ }^{2}$

\section{Results}

\subsection{Determination of model resolution}

In our analysis, the model resolution is determined by performing a 2-dimensional discrete cosine transform (DCT) on the summer rainfall climatology over the SE US. The DCT algorithm decomposes the rainfall data into several harmonic waves (Duhamel and Vetterli 1990). Power spectrum distribution versus wave number (wavelength) can provide information about the characteristic spatial scales of rainfall systems over the SE US (Denis et al. 2002; Bielli and Roca 2010). This information is utilized in this study to configure the spatial resolution of the WRF simulation.

Figure 3 shows the spatial power spectrum of SE US summer rainfall corresponding to the meridional and zonal wave numbers ${ }^{3}$ as calculated using the DCT algorithm (Denis et al. 2002). Over the SE US, a large portion of the power spectrum energy for summer precipitation is concentrated within wave numbers $<40$ (i.e., spatial scales greater than $100 \mathrm{~km}$, or approximately mesoscale). As the spatial scale decreases, the power spectrum energy decreases as well (Fig. 3a). Over the entire domain, rainfall systems with a spatial scale of $60 \mathrm{~km}$ have $<1 \%$ of the power spectrum energy of 1,000-km systems (Fig. 3b). At the same time, the rainfall power spectrum approximates a white spectrum, indicating that rainfall systems with spatial scales $<60 \mathrm{~km}$ are relatively stochastic (Fig. 3b).

According to the power spectrum behavior of SE US summer rainfall, $60 \mathrm{~km}$ is characterized as a cut-off wavelength. Usually, resolving a rainfall system with a $60-\mathrm{km}$ spatial scale requires a model horizontal resolution of about $15 \mathrm{~km}$ (Pielke 2002; Feser et al. 2011). Thus, in

\footnotetext{
2 The 5-day spin-up time is determined based on our 15-day test simulation with various spin-up periods ranging from 0 day to 10 days. The rainfall bias over the SE US domain is calculated and it is found that rainfall bias sharply decreases when spin-up time increases to 3 days and is stabilized afterward. Thus, spin-up period longer than 3 days is needed to ensure the numerical stability of the simulation results. We choose a 5-day period to further ensure the adequacy of the spin-up time.

${ }^{3}$ The wave number in the DCT algorithm can be converted to wavelength by the relationship, where $k=\sqrt{m^{2}+n^{2}}$ is the spatial wave number ( $m$ and $n$ are the zonal and meridional wave numbers, respectively), and $L$ is the length of the analysis domain (Denis et al. 2002).
} 

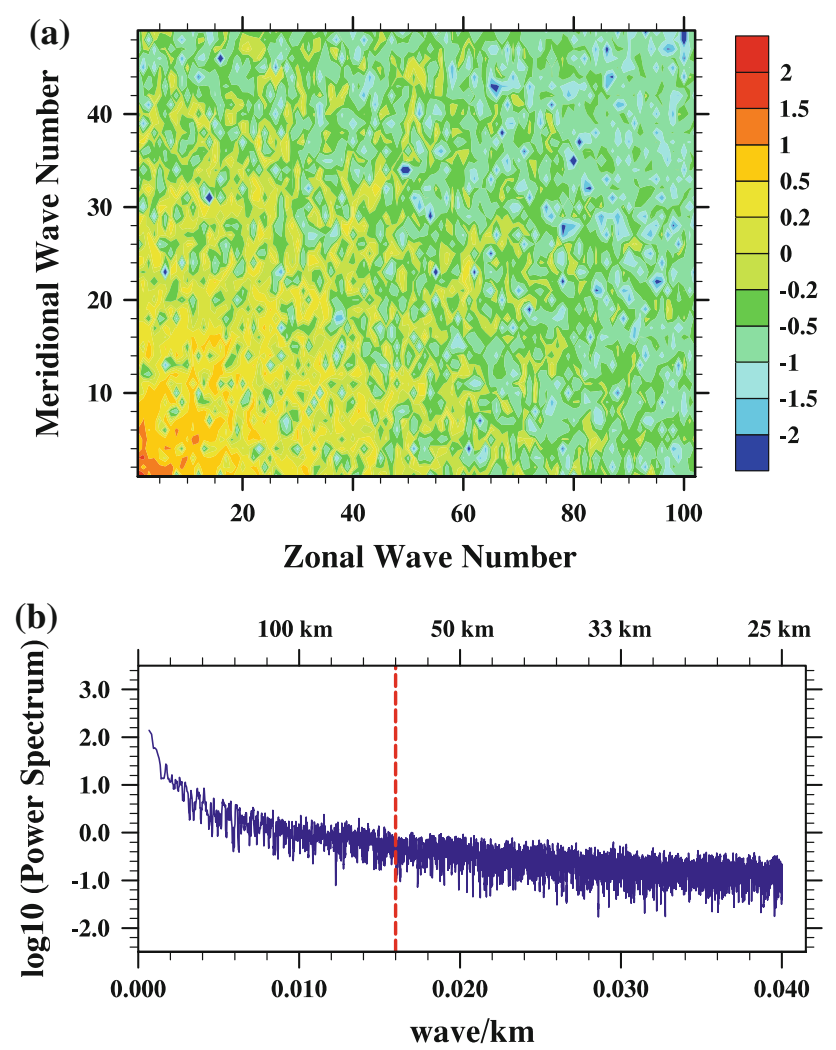

Fig. 3 a Spatial power spectrum (shaded, unit: $\mathrm{mm}^{2} \mathrm{day}^{-2}$ ) of SE US summer precipitation climatology as calculated from discrete cosine transform (DCT); the color scale has been log-scaled; $\mathbf{b}$ power spectrum versus spatial wavelength: the $\mathrm{x}$-axis in the bottom (top) is the number of wave per kilometer (wavelength). The red dashed line denotes wavelength $=60 \mathrm{~km}$, where power spectrum decreases to $1 \%$ of that with the largest wavelength

this study, the WRF simulation is configured at a $15-\mathrm{km}$ horizontal resolution.

\subsection{Influence of physical parameterization on simulation skills}

In this study, we focus on three categories of physical parameterization schemes, that is, microphysics, planetary boundary layer, and cumulus schemes, which are directly related to rainfall processes (e.g., Kunkel et al. 2002; Wisse and Vilà-Guerau de Arellano 2004; Morrison et al. 2009). The eleven microphysics, eight planetary boundary layer, and five cumulus schemes available in WRF ARW 3.4 are investigated. The first set of experiment is to test the sensitivity of WRF simulations to different microphysics schemes, where the planetary boundary layer physics uses the BouLac scheme, and the cumulus scheme uses the BMJ scheme throughout our whole experiments.

To assess the sensitivity of the WRF simulation to physical parameterizations, the Taylor diagram is used (Fig. 4). The Taylor diagram combines the PCC and the ratio of the simulated rainfall standard deviations over those observed (Taylor 2001) and has been widely used to evaluate climate models (e.g., AchutaRao and Sperber 2006; Gleckler et al. 2008). In the Taylor diagram, the distance between the simulated rainfall and observations reflects the model simulation skills (Taylor 2001).

Figure 4 indicates that the WRF simulation skill does not change significantly in response to the different microphysics schemes, as shown in Fig. 4a where the PCC clusters around 0.50 and the ratio of the spatial standard deviation is within a range of $0.63-1.02$. These results imply that the microphysics parameterizations embedded in WRF may be sufficient to represent the microphysical processes in SE US summer rainfall systems.

In the following experiments, we use the Lin microphysics scheme (Lin et al. 1983), which demands the least computing resources and has the relatively high PCC and close to unity standard deviation ratio. At the same time, the BMJ cumulus scheme is used for the iterations of planetary boundary layer experiments. The set of experiments with different planetary boundary layer schemes shows a larger spread in the simulation results than that for microphysics (Fig. 4a, b). This spread comes mainly from the increased range in spatial standard deviations, whereas the PCC is concentrated at around 0.50 (Fig. 4b). Among the tested schemes, the simulation with the MYNN-3 planetary boundary layer physics scheme (Nakanishi and Niino 2006) generates a PCC of 0.55 and the ratio of the spatial standard deviation is 0.87 (Fig. 4b). Synthetically, the simulation by MYNN-3 scheme is the closest to observations (Fig. 4b). Thus, MYNN- $3^{4}$ is adopted in the following sensitivity experiments in which only the cumulus scheme changes.

When the cumulus schemes are varied, the simulation results show an even wider spread (Fig. 4c) than those for the planetary boundary layer physics experiments (Fig. 4b), suggesting that the WRF simulation of SE US summer rainfall is highly sensitive to the cumulus schemes included in the model. In Fig. $4 \mathrm{c}$, the ratios of the spatial standard deviation of SE US summer rainfall show a large range among the cumulus schemes. The Kain-Fritsch (KF) scheme (Kain 2004) produces the largest deviation (3.8 times larger than the observations), while the ZhangMcFarlane scheme (Zhang and McFarlane 1995) produces the deviation value closest to the observations. Overall, the sensitivity experiments reflect the importance of the cumulus schemes in rainfall simulation over the SE US, which has also been emphasized in previous studies (e.g., Jankov et al. 2005; Bukovsky and Karoly 2009).

\footnotetext{
$\overline{4}$ The MYNN-3 scheme is not compatible with the Zhang-McFarlane scheme; thus the UW planetary boundary layer physics scheme is used in the simulation with the Zhang-McFarlane scheme.
} 
Fig. 4 Taylor diagrams evaluating WRF simulation skill of SE US summer precipitation by using different a microphysics (dots); b planetary boundary layer (asterisks); and c cumulus (upward triangles) schemes. The radius represents the ratio between the WRF-simulated and the observed spatial standard deviation of rainfall. The cosine of the angle equals the rainfall pattern correlation coefficients between the WRF simulations and observations
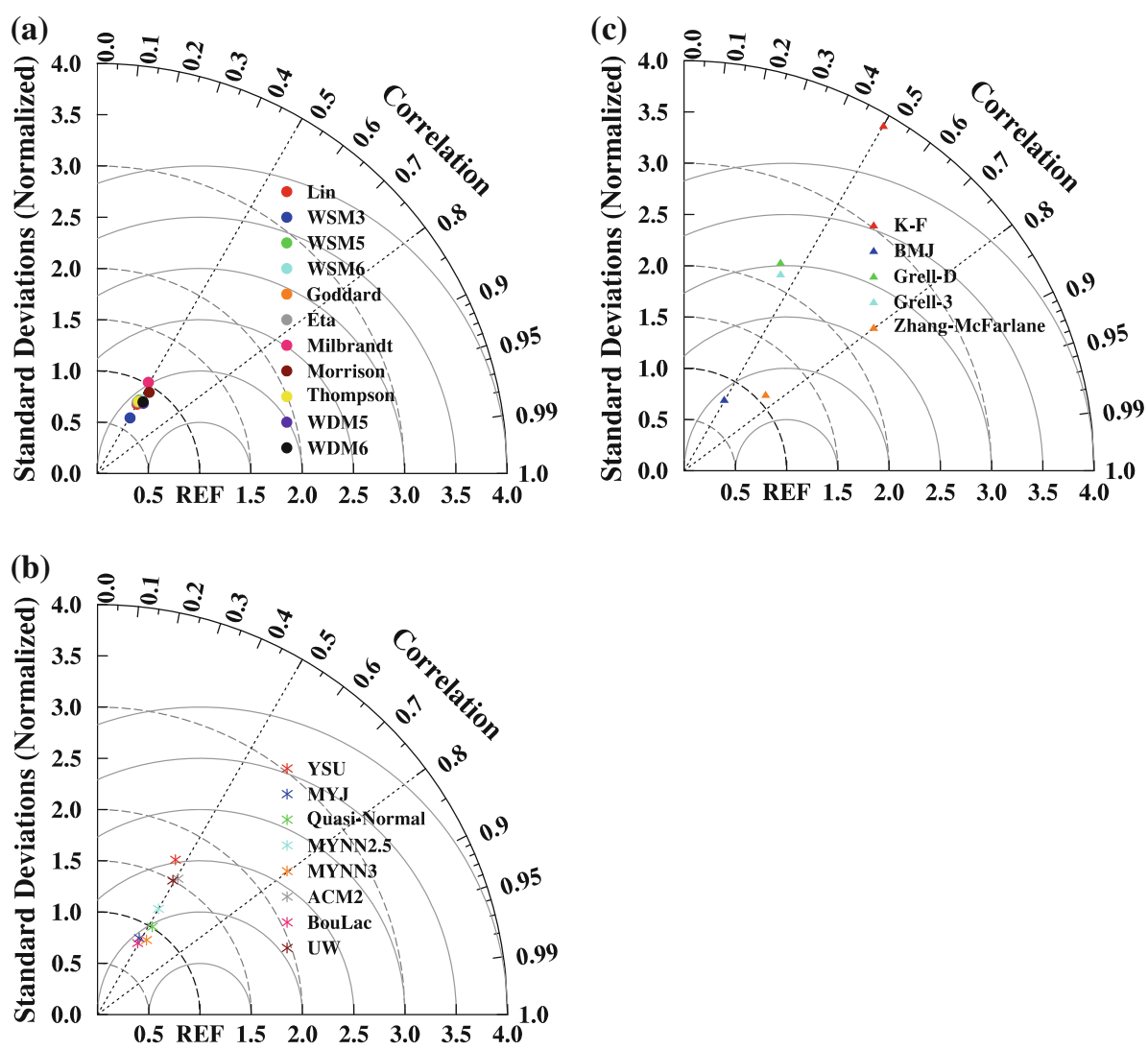

The above analysis suggests that the cumulus schemes affect the WRF simulation skills mainly for SE US summer rainfall. Furthermore, observed evidence shows that SE US summer rainfall, especially its spatial heterogeneity, is controlled largely by convective systems (Konrad 1997; Baigorria et al. 2007; Kunkel et al. 2012), indicating that realistically representing convective processes in cumulus parameterization schemes is important for an accurate simulation of SE US summer rainfall. Thus, an analysis of how cumulus schemes influence SE US summer rainfall simulation is imperative to improving rainfall simulation skills. It can also provide insights into the physical mechanisms of rainfall over the SE US.

The simulated spatial patterns of SE US summer rainfall using different cumulus schemes are compared with observations in Fig. 5, where the simulated rainfall using the K-F, Grell and Dévényi (2002), and Grell-3 (Grell and Dévényi 2002) schemes is overestimated over the SE US (Fig. 5a-c). In particular, all three schemes tend to simulate maximum rainfall over the coast of the Carolinas along with a southwest-northeast-oriented rain belt sweeping the eastern coast of the SE US (Fig. 5a-c). Such a rainfall distribution is not seen in the observations (Fig. 1b). Averaged over the terrestrial area of the SE US, the net wet bias is $\sim 3 \mathrm{~mm} \mathrm{day}^{-1}$ in the simulations using the Grell-
Dévényi or Grell-3 schemes (Fig. 5g, h), and $4.8 \mathrm{~mm} \mathrm{day}^{-1}$ using the $\mathrm{K}-\mathrm{F}$ scheme (Fig. 5f). Rainfall simulated using the BMJ (Fig. 5d) and the ZhangMcFarlane schemes (Fig. 5e) reasonably captures the observed rainfall pattern although the BMJ scheme results in a net dry bias compared to the observations. The underestimation of rainfall with the BMJ scheme is most evident over Florida and the Gulf Coast (Fig. 5i), with a domain-averaged dry bias of $0.8 \mathrm{~mm} /$ day, exceeding one standard deviation of the interannual variation in SE US summer rainfall ( $\mathrm{Li}$ et al. 2013a). Such a rainfall bias is largely reduced in the Zhang-McFarlane scheme, with a domain-averaged bias of $<0.2 \mathrm{~mm} \mathrm{day}^{-1}$ (Fig. 5j). In addition, the Zhang-McFarlance scheme captures well the magnitude and local maximum of the rainfall distribution when compared to the observations (Fig. 5f).

Among the five cumulus schemes tested in this study, the Zhang-McFarlane scheme outperforms the other four in its simulated spatial distribution of rainfall (Fig. 5e, j), domain-averaged rainfall, and the evaluation metrics that are depicted by the Taylor diagrams (Fig. 4c). Thus, the improved WRF simulations of SE US summer rainfall can be generated by applying the Zhang-McFarlane scheme in combination of Lin microphysics and UW planetary boundary layer schemes. 
Fig. 5 SE US summer precipitation (shaded, unit: mm day ${ }^{-1}$ ) during Aug. 1-Aug. 15,2009 , as simulated by WRF with the a K-F; b Grell-

Dévényi; c Grell-3; d BMJ; and e Zhang-McFarlane schemes. $\mathbf{f}-$ $\mathbf{j}$ are the same as $\mathbf{a}-\mathbf{e}$, but showing the simulated bias in precipitation (shaded, unit: $\mathrm{mm}$ day $^{-1}$ ) compared with observations as in Fig. 1b (a)

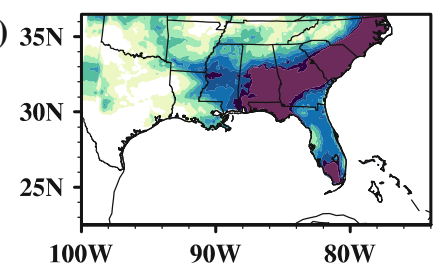

(b)

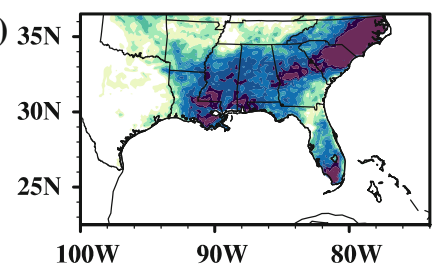

(c)

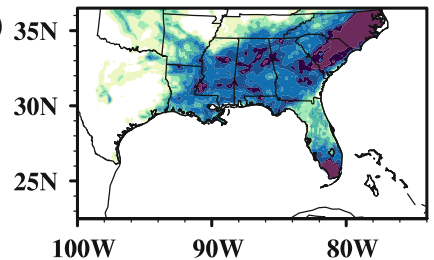

(d)

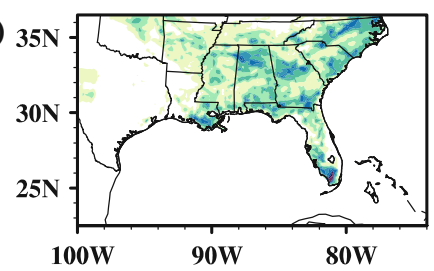

(e)

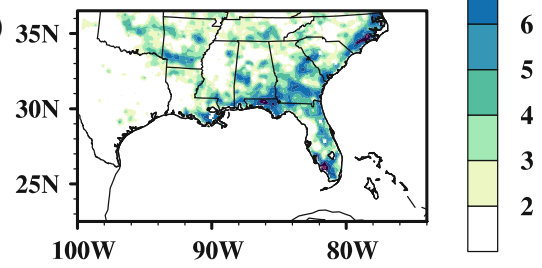

(f)

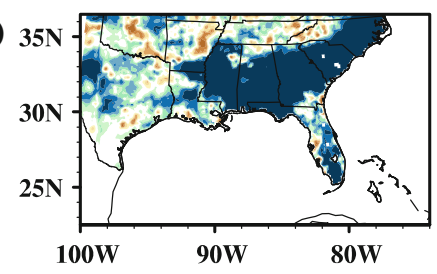

(g)

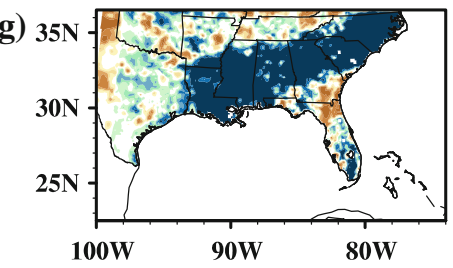

(h)

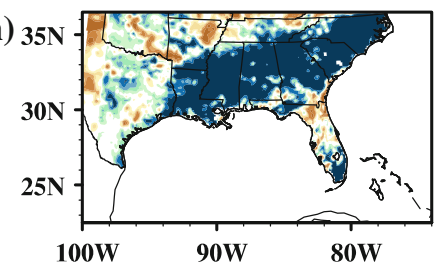

(i)

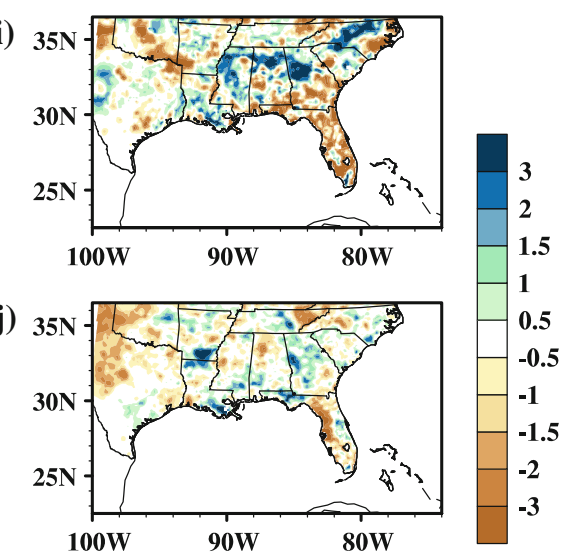

\subsection{Performance of the Zhang-McFarlane and BMJ} scheme in a 10 -year summer rainfall simulation

The sensitivity experiments suggest that the WRF simulation of SE US summer rainfall is most sensitive to the choice of cumulus schemes. To validate this result, two 10-year (2001-2010) simulations are performed. The 10 -year simulation consists of 10 separate summer runs, without applying any nudging skills. Only the ZhangMcFarlane and BMJ schemes $^{5}$ are considered and compared, because both schemes simulate rainfall patterns that are relatively closer to the observations based on the above sensitivity experiments (Fig. 5). Furthermore, the ZhangMcFarlane scheme outperforms all the other schemes,

\footnotetext{
5 The Lin microphysics scheme is used for the 10-yr simulation. For the simulation with Zhang-McFarlane (BMJ) cumulus scheme, UW (MYNN3) planetary boundary layer schemes are used.
}

while BMJ is the only scheme that simulates the dry bias over the SE US (Fig. 5). Thus, the analysis of the rainfall simulations with these two schemes provides us with an understanding of the mechanisms that control the amount of summer rainfall over the SE US.

Figure 6 compares the simulated and observed rainfall during the 10-year period. The observed rainfall shows a sharp spatial gradient along the coastal regions (Fig. 6a), due mainly to land-sea heating contrasts during the summer (Wu et al. 2009) and the contribution of tropical activities (Kunkel et al. 2012). Such a rainfall pattern is generally captured by both schemes (Fig. 6b, c): the simulated summer rainfall is heavier over the coastal regions and decreases inland.

The BMJ scheme, however, underestimates coastal rainfall by $20 \%$, especially over Florida, where the dry bias is more than $2 \mathrm{~mm} \mathrm{day}^{-1}$ (Fig. 6b, d). In contrast, the Zhang-McFarlane scheme not only captures the spatial 
Fig. 6 2001-2010 summer precipitation climatology over the SE US (shaded, unit: $\mathrm{mm}$ day $^{-1}$ ): a observations; and WRF simulations with the b BMJ and c Zhang-McFarlane schemes; their simulation bias (shaded, unit: $\mathrm{mm} \mathrm{day}^{-1}$ ) is shown in $\mathbf{d}$ and $\mathbf{e}$, respectively (a)

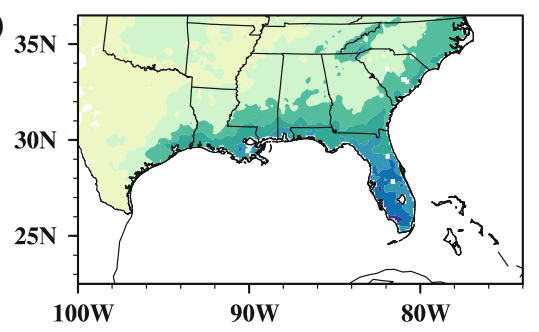

(b)

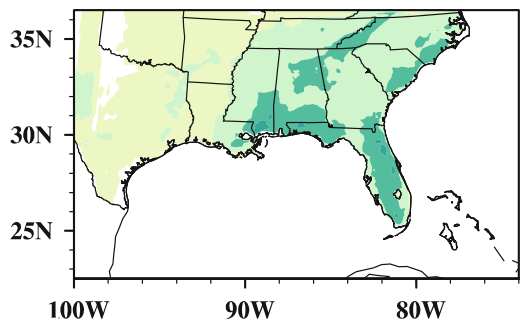

(c)

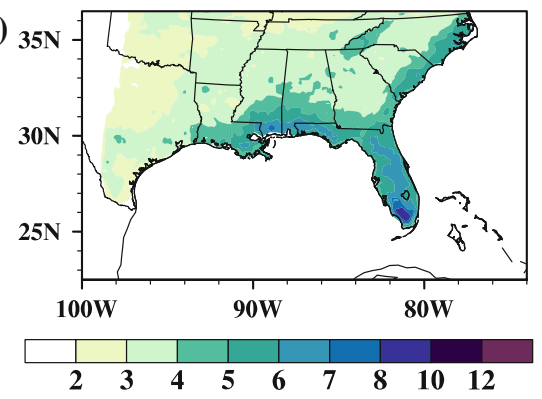

(d)

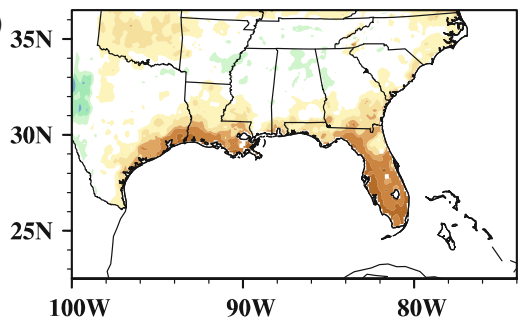

(e) 3

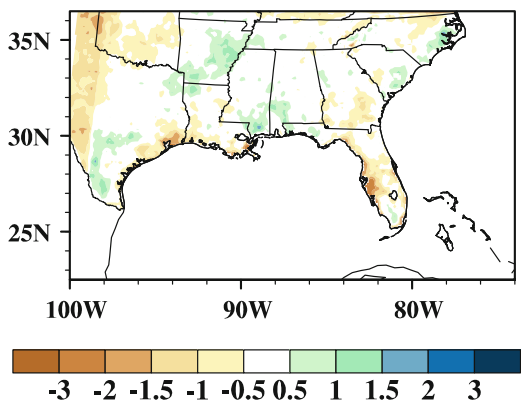

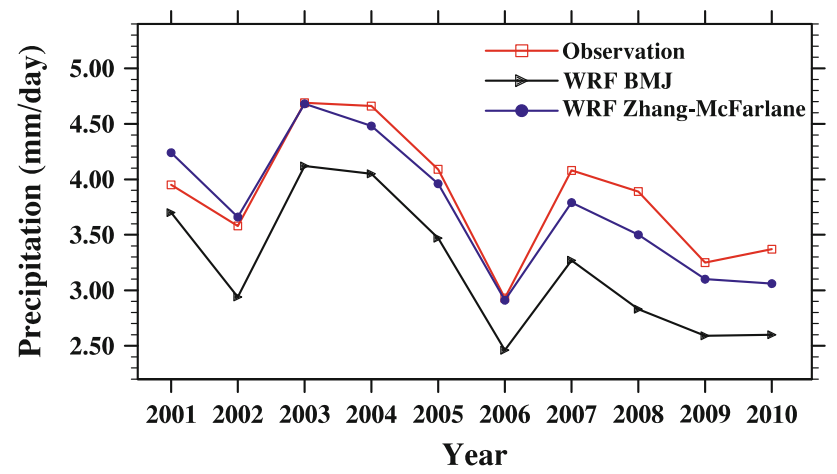

Fig. 7 Interannual variation in summer precipitation (curves, unit: $\mathrm{mm}$ day $\left.^{-1}\right)$ averaged over terrestrial SE US $\left(23^{\circ} \mathrm{N}-36.5^{\circ} \mathrm{N}, 91^{\circ} \mathrm{W}-\right.$ $76^{\circ} \mathrm{W}$ ) during 2001-2010. The red curve is the observations, and the black (blue) curve is the WRF simulation with the BMJ (ZhangMcFarlane) scheme

distribution of the rainfall but also simulates rainfall magnitude that is fairly close to observations (Fig. 6c, e), especially over the coastal regions (Fig. 6b-e). The PCC and RMSE are 0.87 and $0.62 \mathrm{~mm}^{\text {day }}{ }^{-1}$ with the ZhangMcFarlane, respectively, which are better than 0.69 and $1.07 \mathrm{~mm} \mathrm{day}^{-1}$ with the BMJ.

The time series of the domain-averaged simulated summer rainfall are shown in Fig. 7. Due to the substantial dry bias over the coastal regions (Fig. 5e), the BMJ scheme underestimates domain-averaged rainfall by $0.66 \mathrm{~mm} \mathrm{day}^{-1}$. However, the bias simulated by the ZhangMcFarlane scheme is reduced to $0.10 \mathrm{~mm} \mathrm{day}^{-1}$.

The skill scores obtained from this additional 10-year simulation agree well with those from the 15-day sensitivity experiments (Sect. 3.2). This consistency suggests that our statistical method designed to locate a rainfall pattern that resembles its climatology is effective in identifying a representative simulation period for conducting the sensitivity experiments. Such a method should therefore be applicable to regional climate simulations over different regions and temporal periods.

\subsection{Mechanism of cumulus scheme impact on SE US rainfall simulation}

Our analysis pinpoints cumulus schemes as one of the most important elements affecting the ability of WRF to simulate SE US summer rainfall. The influences of cumulus schemes are especially evident over the coastal regions (Fig. 6), where rainfall is tightly associated with convective systems (e.g., Knight and Davis 2007; Kunkel et al. 2012). Understanding how different cumulus schemes generate different spatial patterns and magnitudes of 
Table 1 Description of the cumulus schemes tested in this study

\begin{tabular}{|c|c|c|}
\hline $\begin{array}{l}\text { Cumulus } \\
\text { scheme }\end{array}$ & Mass-flux closure and convection triggering & References \\
\hline $\begin{array}{l}\text { Kain-Fritsch } \\
\quad(\mathrm{K}-\mathrm{F})\end{array}$ & $\begin{array}{l}\text { (a) The scheme uses a simple cloud model with moist updrafts and downdrafts } \\
\text { (b) Deep convection is activated if parcel vertical velocity remains positive over a depth } \\
\text { that exceeds a specified minimum cloud depth } \\
\text { (c) Activated convection has a given updraft mass flux, based on which downdraft mass } \\
\text { flux is estimated according to the relative humidity } \\
\text { (d) Convective available potential energy (CAPE) is used as mass-flux closure. } \\
\text { Convection rearranges mass in the column until at least } 90 \% \text { of the CAPE is removed } \\
\text { (e) Originally developed for mesoscale models }\end{array}$ & $\begin{array}{l}\text { Kain and Fritsch }(1990,1993) \text {, } \\
\text { Kain (2004) }\end{array}$ \\
\hline $\begin{array}{l}\text { Grell-Devenyi } \\
\text { Grell-3 }\end{array}$ & $\begin{array}{l}\text { The Grell-Devenyi and Grell-3 schemes consist of an ensemble of cumulus scheme, in } \\
\text { which multiple schemes are run within each grid box and the results are averaged }\end{array}$ & Grell and Dévényi (2002) \\
\hline $\begin{array}{l}\text { Betts-Miller- } \\
\text { Janjic (BMJ) }\end{array}$ & $\begin{array}{l}\text { (a) The deep convection profiles depend on the cloud efficiency, which in turn depends } \\
\text { on the entropy change, precipitation, and mean temperature of the cloud } \\
\text { (b) Deep convection is triggered only when entropy changes in the cloud pass a } \\
\text { threshold value } \\
\text { (c) In searching for the cloud top, the ascending particle mixes with the environment, } \\
\text { and the work of the buoyancy force on the ascending particle is required to exceed a } \\
\text { prescribed positive threshold } \\
\text { (d) Originally developed for mesoscale models }\end{array}$ & $\begin{array}{l}\text { Betts (1986), Betts and Miller } \\
\text { (1986), Janjic (1994, 2000) }\end{array}$ \\
\hline $\begin{array}{l}\text { Zhang- } \\
\text { McFarlane }\end{array}$ & $\begin{array}{l}\text { (a) The scheme is based on a plume ensemble concept. The drafts have the same initial } \\
\text { mass flux and the entrainment rate depends on the large-scale thermal structure of the } \\
\text { atmosphere } \\
\text { (b) Convection exists only when CAPE consumption is positive } \\
\text { (c) Convection removes CAPE, and the convective precipitation (through the } \\
\text { relationship with updraft mass flux), is proportional to the amount of CAPE in the } \\
\text { atmosphere } \\
\text { (d) Originally developed for GCMs }\end{array}$ & Zhang and McFarlane (1995) \\
\hline
\end{tabular}

rainfall is thus critical to understanding the WRF simulation skill of SE US summer rainfall.

Here, we focus on the Zhang-McFarlane and BMJ schemes by analyzing their 10-year simulation results (Figs. 6, 7). In both schemes, convection adjusts local atmosphere toward defined equilibrium states, and convective precipitation onsets only when certain triggering criteria are met (Janjic 1994, 2000; Zhang and McFarlane 1995; Arakawa 2004). Usually, among different parameterization schemes, the triggering functions differ substantially (Table 1). Thus, rainfall-triggering processes might cause the discrepancies in their simulated rainfall.

To evaluate the rainfall-triggering processes in these two schemes, the number of rainy days during summer seasons was counted. Rainy days are defined as those days when the rain gauge (model grid point) receives more than $0.4 \mathrm{~mm}$ precipitation within $24 \mathrm{~h}$ in observations (WRF simulation). A larger number of rainy days indicate more frequent triggering of rainfall events in the summer. In addition, average storm intensity is defined as the rainfall amount averaged over the rainy days.

The observed number of rainy days shows a spatial pattern that closely resembles the seasonal mean rainfall pattern (Figs. 6a, 8a). A high frequency of rainfall events (more than $70 \%$ of the summer seasons) is observed along the coastal regions (Fig. 8a). In contrast, the average storm intensity does not show a pattern coherent with observations. The observed local maximum of storm intensity is in Oklahoma instead of over the coastal regions where rainfall occurs more frequently (Fig. 8d). Synthetically, on a seasonal scale, SE US summer rainfall, especially the convective rainfall over the coastal regions, is related more to the frequency of rainfall events than to storm intensity (Fig. 8a, d). Such a feature indicates that the parameterization of rainfall-triggering processes is critical to WRF's ability to simulate SE US summer rainfall.

Compared with observations, the better performance of the Zhang-McFarlane scheme is reflected in its simulation accuracy in the number of rainy days. Specifically, the BMJ scheme substantially underestimates the number of rainy days over the coastal regions by about 10 days per summer season, resulting in its dry bias in the seasonal rainfall simulation (Fig. 8b). In contrast, the number of rainy days over the coastal regions is reasonably simulated with the Zhang-McFarlane scheme, with only slight underestimation over Florida ( $\sim 2$ days) (Fig. 8c). Thus, 
Fig. 8 10-year (2001-2010) average number of rainy days (shaded, unit: days) during summer: a observations, and WRF simulations with the b BMJ, and c Zhang-McFarlane schemes; and the average storm intensity (shaded, unit: $\mathrm{mm}$ day $^{-1}$ ) in $\mathbf{d}$ observations, and WRF simulations with the e BMJ, and $\mathbf{f}$ Zhang-McFarlane schemes (a)

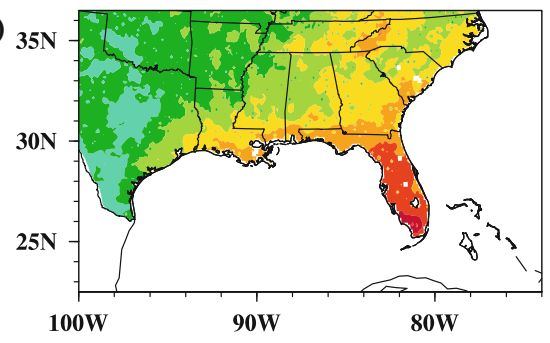

(b)

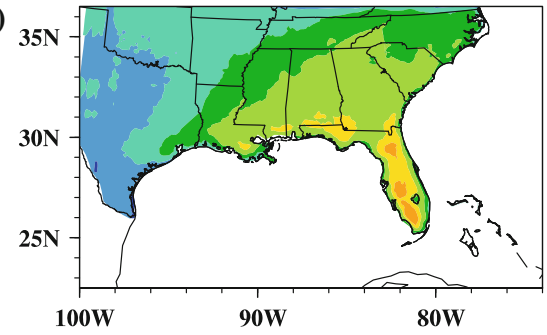

(c)

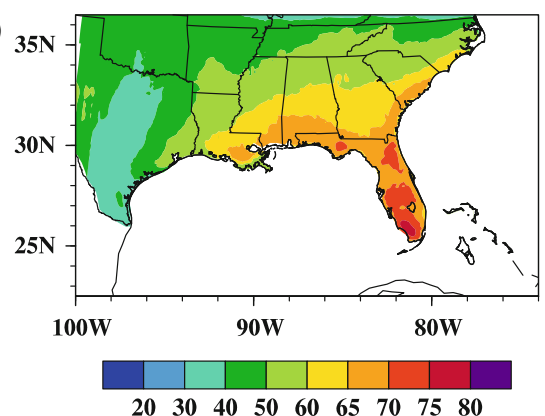

(d) 3

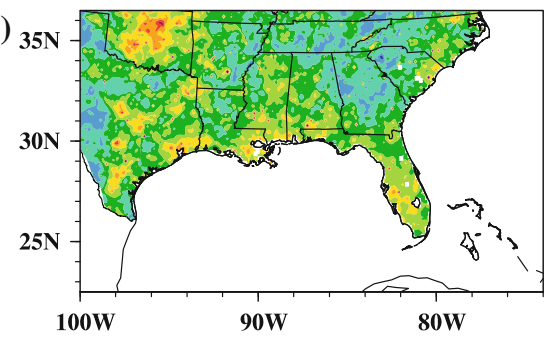

(e)

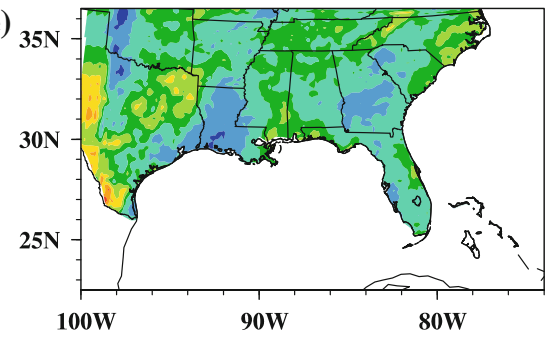

(f) 3

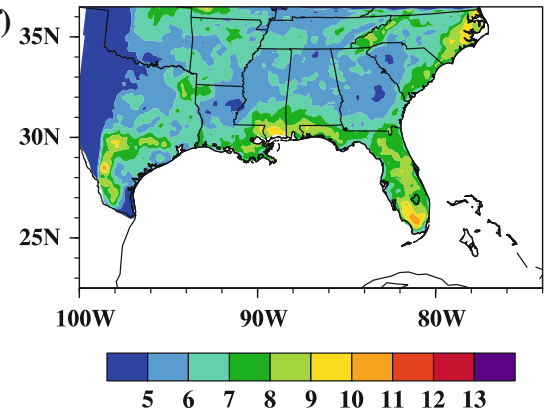

the more realistic performance of the Zhang-McFarlane scheme in simulating SE US summer rainfall relies on its better representation of rainfall-triggering processes.

The reasonable triggering of rainfall events in the Zhang-McFarlane scheme might be due to the assumptions it uses to parameterize cumulus convection (Table 1). The parameterization of the Zhang-McFarlane scheme uses the convective available potential energy (CAPE) (Zhang and McFarlane 1995). CAPE is calculated as the vertically integrated parcel buoyant energy (Moncrieff and Miller 1976) and is usually used to diagnose convection-related activities (e.g., Emanuel 1994; Tompkins 2001; Li and Fu 2004; Stevens 2005; Adams and Souza 2009).

Over the SE US, summer rainfall shows a positive relationship with CAPE (Fig. 9c). The distribution of CAPE almost mirrors the rainfall distribution except in the Appalachian Mountains, where rainfall is mainly forced by orographic lifting (Fig. 9a, c). The correlation between CAPE and summer rainfall is clear over the coastal regions, with a high CAPE corresponding with high rainfall amount and rainy day numbers (Figs. 6a, 8a, 9a, c).

In the Zhang-McFarlane scheme, the CAPE criterion is used to trigger convection in addition to the mass-flux closure for convection (Table 1; Zhang and McFarlane 1995). Constrained by mass-flux closure, the cumulus convection removes CAPE accumulated by large-scale forcing, which acts to stabilize the local atmospheric column (Zhang and McFarlane 1995). Thus, the ZhangMcFarlane scheme implies a positive "CAPE-precipitation" relationship (Fig. 9b, d; Arakawa 2004; Adams and Souza 2009), similar to that observed over the SE US (Fig. 9a, c). As a result, the observed summer rainfall pattern (Fig. 6a) and rainy day number (Fig. 8a) over the SE US are likely to be reproduced by the Zhang-McFarlane scheme, with a more frequent onset of convection leading to stronger seasonal precipitation over the coastal regions (Figs. 6c, 8c; Liu et al. 2010), where CAPE is the highest within the SE US domain (Fig. 9b).

In contrast to the Zhang-McFarlane scheme, the other 4 cumulus schemes fail to capture the observed "CAPEprecipitation" relationship, thus lowering their skills in simulating SE US summer rainfall. Figure 10 illustrates the relationship between CAPE and precipitation as simulated by the other 4 cumulus schemes in the sensitivity experiment. The K-F, Grell-Dévényi, and Grell-3 schemes tend to simulate strong rainfall over regions with low CAPE values (Fig. 10a-c), resulting in an overestimate of precipitation across the SE US (Fig. 5). On the other hand, the BMJ scheme simulates a negative "CAPE-precipitation" relationship over the SE US 

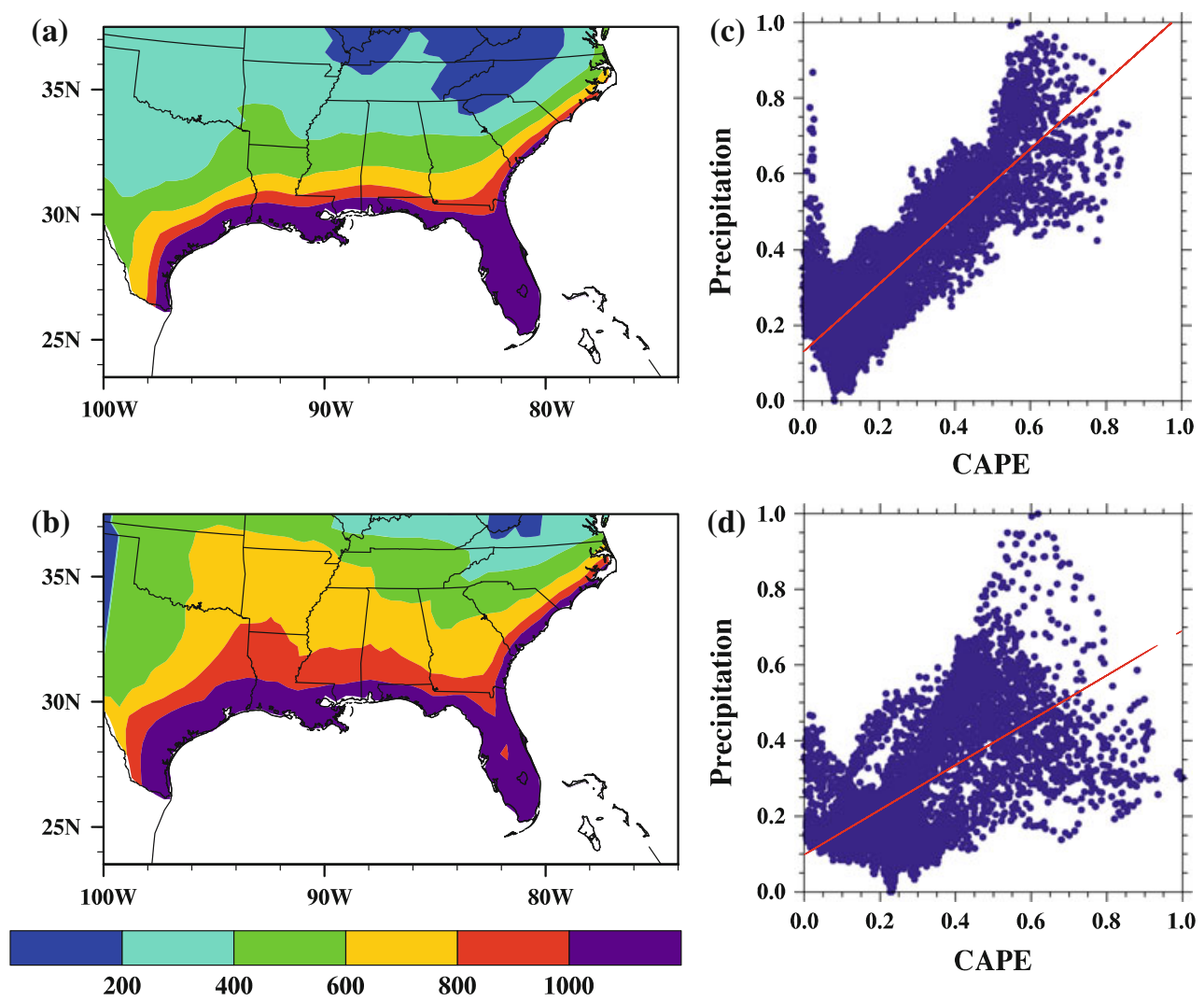

Fig. 9 2001-2010 JJA climatology of convective available potential energy (CAPE) over the SE US (shaded, unit: $\mathrm{J} \mathrm{Kg}^{-1}$ ): a observations; b WRF simulation with the Zhang-McFarlane scheme. $\mathbf{c}$ and $\mathbf{d}$ are the CAPE (normalized) versus summer precipitation (normalized) over the SE US in observations and the WRF simulation with the ZhangMcFarlane scheme, respectively. The red lines in $\mathbf{c}$ and $\mathbf{d}$ are the best least squares fitting lines
(Fig. 10d), which might explain its dry bias over the coastal regions along with its wet bias in the interior domain (Fig. 5i).

The analysis of the relationship between CAPE and precipitation suggests that the representation of this relationship is a key to the high-quality simulations of SE US summer rainfall, whereas the effects of the resolutions on the effectiveness of using the cumulus schemes is less significant. The Zhang-McFarlane scheme was originally developed for GCMs (Zhang and McFarlane 1995), whose grid points are usually of $10^{2} \mathrm{~km}$ (Taylor et al. 2012). In contrast, the other schemes are designed mainly for mesoscale model, indicating that they are supposed to be more skillful in regional climate simulations than the Zhang-McFarlane scheme (Table 1). The better performance of Zhang-McFarlane scheme thus indicates the importance of the representation of physical processes responsible for rainfall generation over the SE US. Overall, the lower skills of these four schemes might be attributed to their inability to capture the observed "CAPE-precipitation" relationship.

\section{Discussion: Choice between a very-high-resolution convection-permitting simulation and a low- resolution Zhang-McFarlane simulation}

Our analysis indicates that cumulus schemes cause the greatest uncertainty in WRF-simulated SE US summer rainfall, compared with microphysics and planetary boundary layer schemes (Figs. 4, 5). Theoretically, the uncertainty from cumulus schemes in rainfall simulations can be eliminated by increasing the WRF resolution to explicitly resolve convective systems (Weisman et al. 1997; Arakawa 2004). Next, we will examine whether using a convection-permitting resolution with WRF improves rainfall simulation over the SE US.

In order to explicitly resolve convective systems, the WRF model is configured over the SE US (Fig. 2) with a $3-\mathrm{km}$ horizontal resolution. The simulation period is Aug. 1-Aug. 15, 2009. The cumulus scheme option is turned off, while the other physical parameterization schemes are the same as in the cumulus scheme sensitivity experiment (see Sect. 3.2). To evaluate the performance of WRF at the 
Fig. 10 CAPE (normalized) versus summer precipitation (normalized) over the SE US in the WRF simulation (blue dots) with the a K-F, b GrellDévényi; c Grell-3, and d BMJ schemes, respectively. The red lines are the best least squares fitting lines
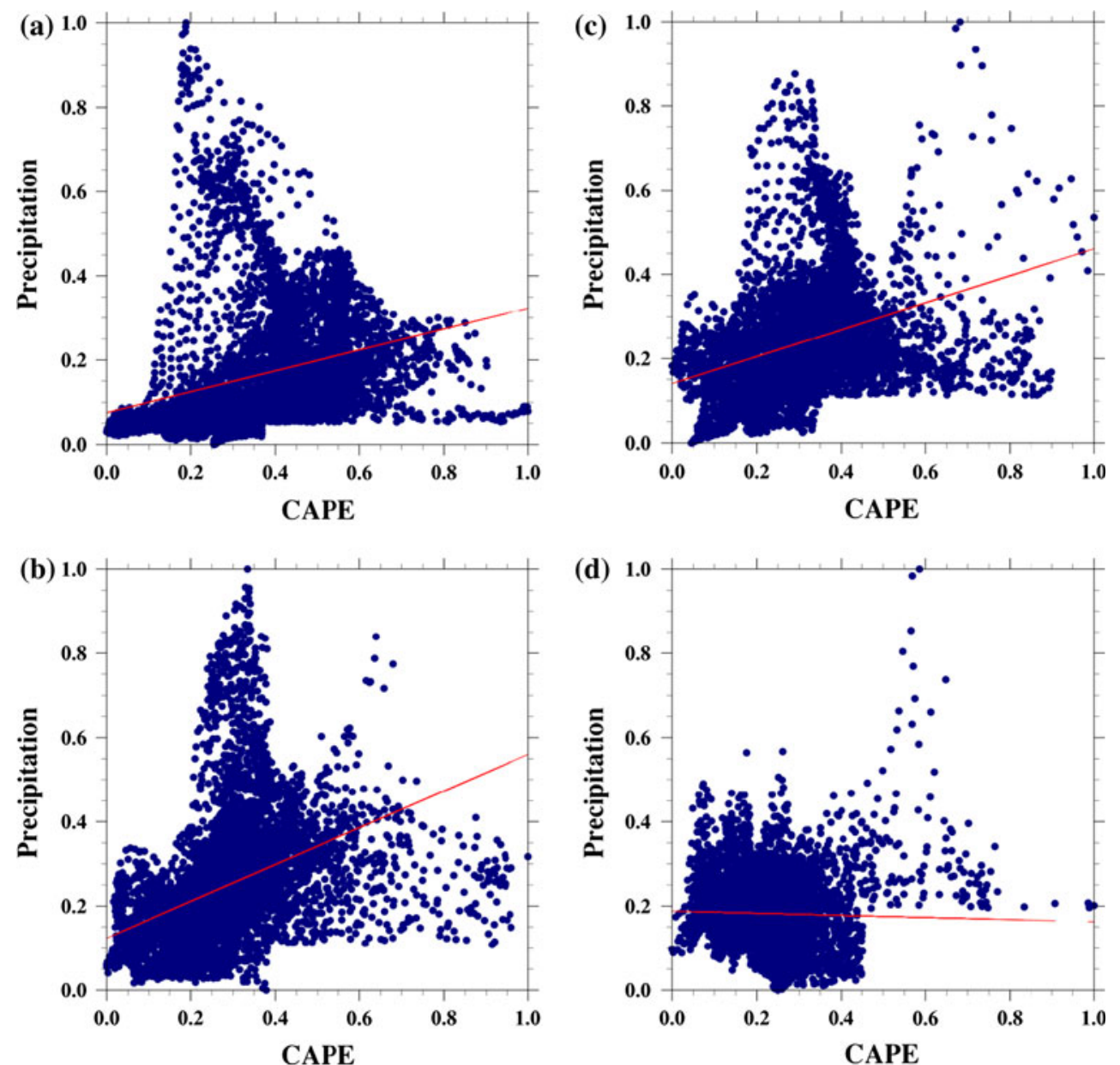

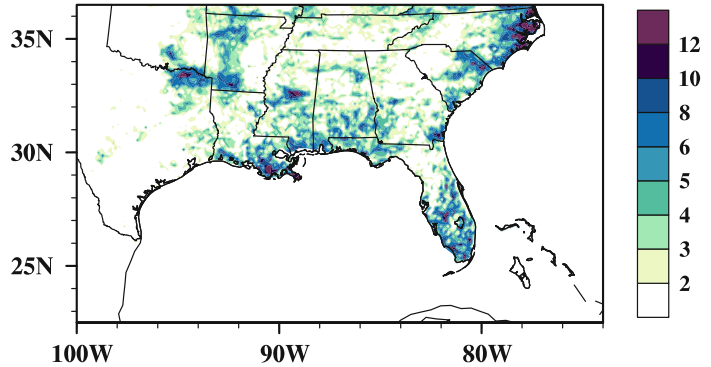

Fig. 11 Aug. 01-Aug. 15, 2009, summer precipitation (shaded, unit: $\mathrm{mm}$ day $^{-1}$ ) as simulated by $3-\mathrm{km}$ WRF convection-permitting configurations; in the simulation, cumulus scheme is turned off and the rainfall is generated only by microphysics

3-km resolution, the Zhang-McFarlane simulations at the $15-\mathrm{km}$ resolution and observations are used for comparison.

Figure 11 shows the rainfall simulated by the $3-\mathrm{km}$ experiment. Generally, with a finer resolution, more local details in rainfall are reflected in the $3-\mathrm{km}$ simulation (Fig. 11) compared to the $15-\mathrm{km}$ simulation (Fig. 5). When compared to the observations, the $3-\mathrm{km}$ simulation captures the high precipitation rate over the coastal regions, although it underestimates the rainfall over Florida and the inland SE US (Fig. 11). Generally, the 3-km simulation outperforms the simulations with the majority of cumulus schemes (Fig. 5a-c), indicating that the convection-permitting approach can improve SE US summer rainfall simulations to some extent. However, the 3-km simulation fails to outperform the $15-\mathrm{km}$ Zhang-McFarlane scheme ${ }^{6}$ : the PCC of the $3-\mathrm{km}$ simulation is only $0.43(0.77$ in Zhang-McFarlane), and its RMSE reaches $2.38 \mathrm{~mm}_{\text {day }}{ }^{-1}$ (1.28 $\mathrm{mm} \mathrm{day}^{-1}$ in Zhang-McFarlane). To avoid the artificially high skill scores of $15-\mathrm{km}$ Zhang-McFarlane scheme due to the usage of relatively coarse resolution observation data $(\sim 25 \mathrm{~km})$, we also calculate the PCC and RMSE using the 4-km Parameter-elevation Regression on

\footnotetext{
${ }^{6}$ The influence of data interpolation methods on the calculation of PCC and RMSE is noticed. Thus, multiple interpolation methods, including the nearest neighbor, kriging, bi-linear interpolation, and cubic spline, are compared. The specific PCC and RMSE values do vary among different methods. However, the conclusion does not change based on qualitative comparison of the $3-\mathrm{km}$ simulation and the Zhang-McFarlane 15-km simulation.
} 
Independent Slope Model (PRISM) data (Daly et al. 2008). The change to higher resolution observations does change the PCC and RMSE values, however, the overall skill scores of the Zhang-McFarlane scheme are still higher than that of the $3-\mathrm{km}$ simulation. Specifically, the PCC is higher, and the RMSE is lower in the 15-km ZhangMcFarlane simulation $(\mathrm{PCC}=0.66$; $\mathrm{RMSE}=1.86$ ) than in the $3-\mathrm{km}$ simulation $(\mathrm{PCC}=0.45 ; \mathrm{RMSE}=2.64)$. Thus, the $15-\mathrm{km}$ Zhang-McFarlane simulation generally outperforms the $3-\mathrm{km}$ simulation. Considering that the 3-km simulation requires 125 times more computational time on our local computing facilities than the $15-\mathrm{km}$ simulation, our results indicate that choosing an optimal cumulus scheme can more effectively improve the simulations of SE US summer rainfall than using a convectionpermitting resolution.

The inferior performance of the 3-km simulation compared to the $15-\mathrm{km}$ Zhang-McFarlane simulation might be caused by multiple factors. First, SE US summer rainfall systems are mainly tropical convective systems, which usually require a resolution finer than $3 \mathrm{~km}$ to fully resolve them (Weisman et al. 1997). Second, it might indicate that SE US summer rainfall is fairly stochastic at spatial scales $<60 \mathrm{~km}$ (Fig. 3). Thus, the physical models cannot provide further improvement in simulation skills even with a fivefold increase in resolution. In addition, the location of the lateral boundaries may also influence to some different extent the skill of high and low resolution RCM simulations. All these hypotheses about WRF simulation skill of SE US summer rainfall need further investigation.

\section{Conclusions}

Regional climate modeling provides important information for climate mitigation and climate policy making over the SE US. However, satisfactory regional climate simulation skills have not yet been achieved over this region, especially for summer rainfall (e.g., Lo et al. 2008; Mearns et al. 2012; Bowden et al. 2013). Some previous studies have emphasized the influences of lateral boundary conditions on SE US rainfall simulation (Castro et al. 2005; Xue et al. 2007). By performing a WRF simulation driven by CFSR data, this study addresses two other important aspects associated with WRF's simulation skills, that is, physical parameterization scheme and model resolution (e.g., Castro et al. 2005; Christensen et al. 2007; Bukovsky and Karoly 2009; Foley 2010; Rummukainen 2010).

Sensitivity experiments are performed to test the WRF simulation skills of SE US summer rainfall in response to various physical parameterization schemes. The period of Aug. 01-Aug. 15, 2009, is chosen as a simulation period because the rainfall pattern averaged over this time span "best" resembles SE US summer rainfall climatology (Fig. 1). The WRF model is configured over the SE US (Fig. 2) with a $15-\mathrm{km}$ resolution according to the DCT analysis (Fig. 3). The sensitivity experiments show that the WRF simulation of SE US summer rainfall is most sensitive to the cumulus schemes in WRF, moderately sensitive to the planetary boundary layer schemes, and least sensitive to the microphysics schemes.

The sensitivity of the rainfall simulation to cumulus schemes indicates the importance of convective systems in the formation of SE US warm-season rainfall patterns (e.g. Konrad 1997; Kunkel et al. 2012), consistent with previous studies (e.g. Bukovsky and Karoly 2009). Among five of the cumulus schemes analyzed in this study, three of them (K-F, Grell-Dévényi, and Grell-3) simulate a strong wet bias, especially over the coast of the Carolinas, causing significant overestimation of rainfall over the region (Fig. 5b-d). In contrast, the BMJ scheme underestimates summer rainfall, resulting in a dry bias, especially over the coastal regions. The Zhang-McFarlane scheme realistically reproduces the observed spatial pattern of rainfall, the domain-averaged rainfall amount, and all the designed evaluation metrics. Thus, based on our simulations, ZhangMcFarlane scheme seems an effective approach to the improvement of SE US summer rainfall simulation by WRF. However, we should make clear that the ZhangMcFarlane scheme might not be the only method to improve SE US summer rainfall simulations. Previous studies have shown that the application of interior grid nudging (e.g. Lo et al. 2008; Bowden et al. 2013), adjustment of parameters in cumulus schemes (e.g. Yang et al. 2012), and the consideration of "cumulus cloud-radiation" feedback in WRF (e.g. Alapaty et al. 2012) can also improve SE US summer rainfall simulation to some extent.

Further analysis suggests that the superior rainfall simulation skills by the Zhang-McFarlane scheme are attributable to its reasonable representation of rainfall-triggering processes over the SE US. The observed number of rainy days over the SE US is accurately simulated by the ZhangMcFarlane scheme, with $<5 \%$ error. The cumulus parameterization in the Zhang-McFarlane scheme implicitly assumes a positive relationship between rainfall and CAPE (Zhang and McFarlane 1995). Such a relationship realistically reflects the summer rainfall pattern over the SE US (except for the Appalachian Mountains) (Fig. 9) and thus improves the WRF simulation skills in SE US summer rainfall using the Zhang-McFarlane scheme.

WRF rainfall simulation with the Zhang-McFarlane scheme at the $15-\mathrm{km}$ resolution is also compared with that produced using a $3-\mathrm{km}$ convection-permitting resolution where cumulus scheme is turned off. The PCC and RMSE indicate that the 3-km simulation does not outperform the 15-km Zhang-McFarlane simulation (Fig. 11). On top of 
that, the $3-\mathrm{km}$ simulation takes 125 times more computational time on our local computing platform. Thus, our analysis suggests that selecting an optimal cumulus parameterization scheme is an effective way to obtain a satisfactory simulation of SE US summer rainfall. This study provides an important tool for reliable future climate forecasts and informed water resource management over the region.

Acknowledgments The authors thank Drs. Fei Chen, Xin-Zhong Liang, and Liang Guo for insightful discussions and comments; Drs. Ying Li, Lin Zhao, and Mr. Haifeng Zhuo for technical support; and the two anonymous reviewers who provide numerous helpful suggestions to improve the manuscript. This work is supported by NSF AGS 1147608, NIH-1R21AG044294-01A1, and NSF-EF-1065730.

\section{References}

AchutaRao KM, Sperber KR (2006) ENSO simulation in coupled ocean-atmosphere models: are the current models better? Clim Dyn 27:1-15

Adams DK, Souza EP (2009) CAPE and convective events in the Southwest during the North American monsoon. Mon Wea Rev 137:83-98

Alapaty K, Herwehe JA, Otte TL, Nolte CG, Bullock OR, Mallard MS, Kain JS, Dudhia J (2012) Introducing subgrid-scale cloud feedbacks to radiation for regional meteorological and climate modeling. Geophys Res Lett 39:L24809

Arakawa A (2004) The cumulus parameterization problem: past, present, and future. J Clim 17:2493-2525

Baigorria GA, Jones JW, O'Brien JJ (2007) Understanding rainfall spatial variability in southeast USA at different timescales. Int $\mathbf{J}$ Climatol 27:749-760

Bielli S, Roca R (2010) Scale decomposition of atmospheric water budget over West Africa during the monsoon 2006 from NCEP/ GFS analyses. Clim Dyn 35:143-157

Betts AK (1986) A new convective adjustment scheme. Part I: Observational and theoretical basis. Quart J Roy Meteor Soc 112:677-691

Betts AK, Miller MJ (1986) A new convective adjustment scheme. Part II: Single column tests using GATE wave, BOMEX, ATEX and arctic air-mass data sets. Quart J Roy Meteor Soc 112:693-709

Bougeault P, LaCarrere P (1989) Parameterization of orographyinduced turbulence in a mesobeta-scale model. Mon Wea Rev 117:1871-1890

Bowden JH, Nolte CG, Otte TL (2013) Simulating the impact of the large-scale circulation on the 2-m temperature and precipitation climatology. Clim Dyn 40:1903-1920

Bukovsky MS, Karoly DJ (2009) Precipitation simulations using WRF as a nested regional climate model. J Appl Meteor Climatol 48:2152-2159

Castro CL, Pielke RA Sr, Leoncini G (2005) Dynamical downscaling: assessment of value retained and added using the regional atmospheric modeling system (RAMS). J Geophys Res 110:D05108

Chen F, Dudhia J (2001) Coupling an advanced land-surface/ hydrology model with the Penn State/NCAR MM5 modeling system. Part I: model description and implementation. Mon Wea Rev 129:569-585

Christensen JH et al (2007) Regional climate projections. In: Solomon S, Qin D, Manning M, Chen Z, Marquis M et al (eds) Climate change 2007: the physical science basis. Contribution of working group I to the fourth assessment report of the intergovernmental panel on climate change. Cambridge University Press, Cambridge and New York

Daly C, Halbleib M, Smith JI, Gibson WP, Doggett MK, Taylor GH, Curtis J, Pasteris PA (2008) Physiographically-sensitive mapping of temperature and precipitation across the conterminous United States. Int J Climatol 28:2031-2064

Dee DP et al (2011) The ERA-interim reanalysis: configuration and performance of the data assimilation system. Quart JR Meteorol Soc 137:553-597

Denis B, Côté J, Laprise R (2002) Spectral decomposition of twodimensional atmospheric fields on limited-area domains using the discrete cosine transform (DCT). Mon Weather Rev 130:1812-1829

Dudhia J (1989) Numerical study of convection observed during the winter monsoon experiment using a mesoscale two-dimensional model. J Atmos Sci 46:3077-3107

Duhamel P, Vetterli M (1990) Fast Fourier transforms: a tutorial review and a state of the art. Signal Process 19:259-299

Emanuel KA (1994) Atmospheric convection. Oxford University Press, Oxford

Feser F, Rockel B, Von Storch H, Winterfeldt JRG, Zahn M (2011) Regional climate models add value to global model data. Bull Am Meteorol Soc 92:1181-1192

Foley AM (2010) Uncertainty in regional climate modeling: a review. Prog Phys Geogr 34:647-670

Giorgi F, Mearns LO (1999) Introduction to special section: regional climate modeling revisited. J Geophys Res 104:6335-6352

Gleckler PJ, Taylor KE, Doutriaux C (2008) Performance metrics for climate models. J Geophys Res 113:D06104

Grell GA, Dévényi D (2002) A generalized approach to parameterizing convection combining ensemble and data assimilation techniques. Geophys Res Lett 29(14):1-38

Higgins RW, Shi W, Yarosh E, Joyce R (2000) Improved United States precipitation quality control system and analysis. NCEP/ climate prediction center ATLAS No. 7, 40 pp, Camp Springs, MD 20746, USA

Janjic ZI (1994) The step-mountain eta coordinate model: further developments of the convection, viscous sublayer and turbulence closure schemes. Mon Weather Rev 122:927-945

Janjic ZI (2000) Comments on "Development and evaluation of a convection scheme for use in climate models". J Atmos Sci $57: 3686$

Jankov I, Gallus WA, Segal M, Shaw B, Koch SE (2005) The impact of different WRF model physical parameterizations and their interactions on warm season MCS rainfall. Weather Forecast 20:1048-1060

Kain JS (2004) The Kain-Fritsch convective parameterization: an update. J Appl Meteorol 43:170-181

Kain JS, Fritsch JM (1990) A one-dimensional entraining/detraining plume model and its application in convective parameterization. J Atmos Sci 47:2784-2802

Kain JS, Fritsch JM (1993) Convective parameterization for mesoscale models: the Kain- Fritsch scheme. The representation of cumulus convection in numerical models. Meteorological Monographs, vol 24. American Meteorological Society, Boston, pp $165-170$

Kanamitsu M, Ebisuzaki W, Woollen J, Yang S-K, Hnilo JJ, Fiorino M, Potter GL (2002) NCEP-DOE AMIP-II reanalysis (R-2). Bull Am Meteorol Soc 83:1631-1643

Knight DB, Davis RE (2007) Climatology of tropical cyclone rainfall in the southeastern United States. Phys Geogr 28:126-147

Konrad CE (1997) Synoptic-scale features associated with warm season heavy rainfall over the interior southeastern United States. Weather Forecast 12:557-571 
Kunkel KE, Andsager K, Liang X-Z, Arritt RW, Takle ES, Gutowski WJ, Pan Z (2002) Observations and regional climate model simulations of heavy precipitation events and seasonal anomalies: a comparison. J Hydrometeorol 3:322-334

Kunkel KE, Eastering DR, Kristovich DAR, Gleason B, Stoecker L, Smith R (2012) Meteorological causes of the secular variations in observed extreme precipitation events for the conterminous United States. J Hydrometeorol 13:1131-1141

Leung LR, Mearns LO, Giorgi F, Wilby RL (2003) Regional climate research: needs and opportunities. Bull Am Meteorol Soc 84:89-95

Li W, Fu R (2004) Transition of the large-scale atmospheric and land surface conditions from dry to wet season over Amazonia as diagnosed by the ECMWF reanalysis. J Clim 17:2637-2651

Li W, Li L, Fu R, Deng Y, Wang H (2011) Changes to the North Atlantic subtropical high and its role in the intensification of summer rainfall variability in the Southeastern United States. J Clim 24:1499-1506

Li L, Li W, Deng Y (2013a) Summer rainfall variability over the Southeastern United States in the 21st century as assessed by the CMIP5 models. J Geophys Res 118:340-354

Li L, Li W, Barros AP (2013b) Atmospheric moisture budget and its regulation of the summer precipitation variability over the Southeastern United States. Clim Dyn 41:613-631

Liang X-Z, Kunkel KE, Samel AN (2001) Development of a regional climate model for US Midwest applications. Part I: sensitivity to buffer zone treatment. J Clim 14:4363-4378

Lin YL, Farley RD, Orville HD (1983) Bulk parameterization of the snow field in a cloud model. J Clim Appl Meteorol Climatol 22:1065-1092

Liu Y, Guo L, Wu G, Wang Z (2010) Sensitivity of ITCZ configuration to cumulus convective parameterizations on an aqua-planet. Clim Dyn 34:223-240

Lo JCF, Yang ZL, Pielke RA Sr (2008) Assessment of three dynamical climate downscaling methods using the weather research and forecasting (WRF) model. J Geophys Res 113:D09112

Manuel J (2008) Drought in the southeast: lessons for water management. Environ Health Perspect 116:A168-A171

Martinez CJ, Baigorria GA, Jones JW (2009) Use of climate indices to predict corn yields in southeast USA. Int $\mathrm{J}$ Climatol 29:1680-1691

Mearns LO, Giorgi F, McDaniel L, Shields C (2003) Climate scenarios for the southeastern U.S. based on GCM and regional model simulations. Clim Chang 60:7-35

Mearns LO et al (2012) The North American regional climate change assessment program: overview of phase I results. Bull Am Meteorol Soc 93:1337-1362

Mesinger F et al (2006) North American regional reanalysis. Bull Am Meteorol Soc 87:343-360

Mlawer EJ, Taubman SJ, Brown PD, Iacono MJ, Clough SA (1997) Radiative transfer for inhomogeneous atmosphere: RRTM, a validated correlated-k model for the long-wave. J Geophys Res 102(D14):16663-16682

Moncrieff M, Miller M (1976) The dynamics and simulation of tropical cumulonimbus and squall lines. Quart J R Meteorol Soc 102:373-394

Morrison H, Thompson G, Tatarskii V (2009) Impact of cloud microphysics on the development of trailing stratiform precipitation in a simulated squall line: comparison of one- and twomoment schemes. Mon Wea Rev 137:991-1007
Nakanishi M, Niino H (2006) An improved Mellor-Yamada level-3 model: its numerical stability and application to a regional prediction of advection fog. Bound Layer Meteorol 119:397-407

Riha SJ, Wilks DS, Simoens P (1996) Impact of temperature and precipitation variability on crop model predictions. Clim Chang 32:293-311

Rummukainen M (2010) State-of-the-art with regional climate models. WIREs Clim Chang 1:82-96

Saha $\mathrm{S}$ et al (2010) The NCEP climate forecast system reanalysis. Bull Am Meteorol Soc 91:1015-1057

Seth A, Giorgi F (1998) The effects of domain choice on summer precipitation simulation and sensitivity in a regional climate model. J Clim 11:2698-2712

Skamarock WC, Klemp JB, Dudhia J, Gill DO, Barker DM, Duda MG, Huang X-Y, Wang W, Powers JG (2008) A description of the advanced research WRF version 3, $125 \mathrm{pp}$, NCAR Tech. Note NCAR/TN-475+STR

Sr Pielke RA (2002) Mesoscale meteorological modeling, 2nd edn. Elsevier, New York

Stevens B (2005) Atmospheric moist convection. Annu Rev Earth Planet Sci 33:605-643

Stooksbury DE, Michaels PJ (1991) Cluster analysis of Southeastern U.S. climate stations. Theor Appl Climatol 44:143-150

Taylor KE (2001) Summarizing multiple aspects of model performance in a single diagram. J Geophysics Res 106(D7): 7183-7192

Taylor KE, Stouffer RJ, Meehl GA (2012) An overview of CMIP5 and the experiment design. Bull Am Meteorol Soc 93:485-498

Thompson G, Field PR, Rasmussen RM, Hall WD (2008) Explicit forecasts of winter precipitation using an improved bulk microphysics scheme. Part II: implementation of a new snow parameterization. Mon Weather Rev 136:5095-5115

Tompkins A (2001) Organization of tropical convection in low vertical wind shears: the role of water vapor. J Atmos Sci 58:529-545

Walker MD, Diffenbaugh NS (2009) Evaluation of high-resolution simulations of daily-scale temperature and precipitation over the United States. Clim Dyn 33:1131-1147

Wang H, Fu R, Kumar A, Li W (2010) Intensification of summer rainfall variability in the Southeastern United States during recent decades. J Hydrometeorol 11:1007-1018

Weisman ML, Skamarock WC, Klemp JB (1997) The resolution dependence of explicitly modeled convective systems. Mon Weather Rev 125:527-548

Wisse JSP, Vilà-Guerau de Arellano J (2004) Analysis of the role of the planetary boundary layer schemes during a severe convective storm. Ann Geophys 22:1861-1874

Wu G, Liu Y, Zhu X, Li W, Ren R, Duan A, Liang X (2009) Multiscale forcing and the formation of subtropical desert and monsoon. Ann Geophys-Ger 27:3631-3644

Xue Y, Vasic R, Janjic Z, Mesinger F, Mitchell KE (2007) Assessment of dynamic downscaling of the continental US regional climate using the $\mathrm{Eta} / \mathrm{SSiB}$ regional climate model. J Clim 20:4172-4193

Yang B, Qian Y, Lin G, Leung R, Zhang Y (2012) Some issues in uncertainty quantification and parameter tuning: a case study of convective parameterization scheme in the WRF regional climate model. Atmos Chem Phys 12:2409-2427

Zhang GJ, McFarlane NA (1995) Sensitivity of climate simulations to the parameterization of cumulus convection in Canadian climate center general circulation model. Atmos Ocean 33:407-446 